\title{
Patterns of perceptions of workplace violence in the Portuguese health care sector
}

\author{
Paulo Ferrinho*1,5, André Biscaia1,2, Inês Fronteira1,3, Isabel Craveiro1,3, \\ Ana Rita Antunes ${ }^{1}$, Claudia Conceição ${ }^{1,3}$, Isabel Flores ${ }^{4}$ and Osvaldo Santos
}

\begin{abstract}
Address: ${ }^{1}$ AGO - Associação para o Desenvolvimento e Cooperação Garcia de Orta, Lisbon, Portugal, ${ }^{2}$ APMCG - Associação Portuguesa de Médicos de Clínica Geral, Lisbon, Portugal, ${ }^{3}$ ENSP - Escola Nacional de Saúde Pública, Universidade Nova de Lisbon, Lisbon, Portugal, ${ }^{4}$ ESEFG - Escola Superior de Enfermagem de Francisco Gentil, Lisbon, Portugal and ${ }^{5}$ IMP-FM - Instituto de Medicina Preventiva, Faculdade de Medicina, Universidade de Lisboa, Lisbon, Portugal

Email: Paulo Ferrinho* - pferrinho@sapo.pt; André Biscaia - nop26631@mail.telepac.pt; Inês Fronteira - inesfronteira@netcabo.pt; Isabel Craveiro - isabelcraveiro@hotmail.com; Ana Rita Antunes - arantunes@portugalmail.pt; Claudia Conceição - claudiac@esoterica.pt; Isabel Flores - iflores@esefg.pt; Osvaldo Santos - osvaldosantos@netcabo.pt

* Corresponding author
\end{abstract}

This article is available from: http://www.human-resources-health.com/content/I/I/I I

(C) 2003 Ferrinho et al; licensee BioMed Central Ltd. This is an Open Access article: verbatim copying and redistribution of this article are permitted in all media for any purpose, provided this notice is preserved along with the article's original URL.

\begin{abstract}
This article characterizes the problem of violence against health professionals in the workplace (VAHPITWP) in selected settings in Portugal. It addresses the questions of what types of violence are most frequent and who are the most affected health professionals.

Three methodological approaches were followed: (i) documentary studies, (ii) a questionnairebased hospital and health centre $(\mathrm{HC})$ complex case study and (iii) semi-structured interviews with stakeholders.

Of the different types of violence, all our study approaches confirm that verbal violence is the most frequent. Discrimination, not infrequent in the hospital, seems to be underestimated by the stakeholders interviewed. Violence seems much more frequent in the $\mathrm{HC}$ than in the hospital. In the $\mathrm{HC}$, all types of violence are also most frequently directed against female health workers and, in the hospital, against male workers.
\end{abstract}

These studies allow us to conclude that violence is frequent but underreported.

\section{Introduction}

Portugal is a country where the National Health Service (NHS) is a relatively recent institution (early 1980s). As part of the development of the Portuguese NHS, health centres (HCs) first made their appearance in the late 1970s, and the family physician (general practitioners GP) in the early 1980s. Until recently, primary health care services were managed as a central vertical programme, in parallel with hospital services, another vertical programme. It is only in the last decade that a major effort has been made to merge multiple directorates into a single Department of Health that acts as a central focal point of policies, strategies, norms and guidelines to be adapted and implemented by five decentralised Regional Health Authorities (RHA). Since 2001, the central administration has been coordinated by a High Commissioner for Health.

The period between 1995 and 1999 was very rich in terms of a new vision of the NHS - more integrated, more 
entrepreneurial, more responsive to the citizens of the country, more information-driven and evidence-based. As a result of this period of reform [1], for the first time there was in Portugal a concerted effort to write a strategic plan, flowing from explicit policies and with identifiable shortterm to long-term targets [2]. An important component of this plan is the development of strategies to ensure greater dignity in professional practice. This last aspect has been restated in all yearly action plans of the Ministry of Health, including the most recent [3].

Portugal's five health regions are divided into subregions (one to six per region). The region chosen by convenience for this study includes one of the two largest metropolitan areas in Portugal, with a population of over three million (about $30 \%$ of the Portuguese population), $24 \%$ of all the hospitals, $12 \%$ of all hospital beds and $19 \%$ of the national total for HCs (not including mental health facilities).

\section{The Portuguese health care human resources in the European Union context}

In the European Union, the human resources scenario in the health sector is (with the exceptions of Ireland, Sweden and the United Kingdom) employing more and more resources. These resources are characterised by an increasing feminisation and specialisation (with the exception of Denmark), a slow increase of nurses as a percentage of the health personnel (with the exception of Finland), and a decreasing concentration of the health personnel in hospitals (with the exception of Portugal). Although the number of medical general practitioners per 1000 population is increasing, its percentage of the total health employment is decreasing (except for Sweden). The number of physicians per 1000 population ranges from 1.7 for the United Kingdom to 5.8 for Italy (3.1 for Portugal); of GPs from 0.4 for Ireland to 1.6 for Finland (0.6 for Portugal); of specialized physicians from 0.1 for Denmark to 2.2 for Germany (1.3 for Portugal); of registered nurses from 3.7 for Portugal to 15.3 for Ireland; of pharmacists from 0.2 for The Netherlands and Denmark to 1.4 for Finland ( 0.7 for Portugal); and of dentists from 0.3 for Portugal to 1.1 for Greece [4].

A significant aspect of the human resources scene in Portugal is that most doctors (over 90\%) are public servants, and more than half of these combine their public sector position with work in the nongovernmental sector [5].

\section{Objectives}

This article characterizes the problem of violence against health professionals in the workplace (VAHPITWP) in selected settings in Portugal. It addresses the questions of what types of violence are most frequent and who are the most affected health professional groups.

\section{Populations and methods}

The study is divided into four parts: documentary studies, hospital case study, health centre complex case study and stakeholders' study. The definitions of violence adopted for the study are presented as an annex at the end of the article.

\section{Documentary studies}

The documentary studies include a review of the professional literature and content analysis of institutional documents and of media articles.

\section{Literature review}

The strategy for identifying the documents reviewed was the following:

- Several data bases (the document information centers of the Escola Superior de Enfermagem de Francisco Gentil (Francisco Gentil Nursing School), Centro de Estudos Judiciais (Centre for Legal Studies), Faculdade de Medicina de Lisboa (Lisbon Faculty of Medicine), Departamento de Sociologia da Universidade de Coimbra (Sociology Department of the University of Coimbra), Instituto Superior de Economia $e$ Gestão de Évora (Evora Insitute of Managements and Economics), Escola Nacional de Saúde Pública (National School of Public Health), INDICT, National Library) were searched for publications from 1990 onwards.

- The informants for the stakeholders' study were asked about literature on VAHPITWP. The key words used to search for the documents were: stress, occupational stress, health professionals' occupational stress, burnout, professional satisfaction, violence, occupational violence, violence in the health sector, aggression, rape, insult and injuries, hospital, health centre, doctor, nurse. The articles were then scanned for explicit references to violence and only these were included. The articles were also scanned for relevant bibliographical references, which were then retrieved and analysed.

\section{Institutional documents}

Official reports from hospitals and health centres of incidents and accidents (in which violence was the cause) were analysed. These reports, mostly by the health professionals victimized by the violence, were included only if they occurred between June 1998 and May 2001. The institutions included for this part of the study are the same as the institutions selected and included in the hospital, $\mathrm{HC}$ and stakeholders studies.

\section{National press analysis}

All the published newspaper articles on VAHPITWP between June 2000 and May 2001 were analysed. The inclusion criteria were: being part of the "Manchete, Portugal" database of daily and weekly newspaper articles, 
available at the Escola Nacional de Saúde Pública (National School of Public Health); being a news article, an editorial, an opinion article or a letter from the reader; having an implicit or explicit reference to VAHPITWP; publication date between June 2000 and May 2001.

The database was searched by means of key words such as: stress, occupational stress, health professionals' occupational stress, burnout, professional satisfaction, violence, occupational violence, violence in the health sector, aggression, rape, insult and injuries, hospital, health centre, doctor, nurse. The articles were then scanned for explicit references to violence and only these were included.

\section{Hospital and HC case studies}

These case studies entailed the adaptation and the application of an international questionnaire for the detection of VAHPITWP (developed by an international consortium of the International Labour Organization, the World Health Organization, the International Council of Nurses and Public Service International) to all the health professionals of the selected district hospital and HC.

The hospital was selected because it had the support of its management board for the study; is a medium-sized district hospital; and serves a fast-growing suburban area in one of the two main metropolitan areas of Portugal, as well as a rural population.

The HC complex was selected because it is large. It is composed of four primary health care units, run mostly by general practitioners and nurses. It also includes a unit for the treatment of patients with tuberculosis. A unit for the ambulatory treatment of psychiatric patients was also included, although not formally part of the $\mathrm{HC}$ (it is a community-based extension of the psychiatric hospital services). The HC functions from 08.00 till 22.00, Monday to Saturdays.

The hospital fieldwork took place during the week of 24 September and 25-27 October 2001 (to follow-up nonrespondents). The HC study was carried out during two days in October 2001. Non-respondents at the first attempt were contacted two further times. If these two repeat contacts failed, those health workers were considered as non-respondents.

\section{Data analysis}

The data, once collected, were entered into a SPSS (Statistical Package for the Social Sciences) database, cleaned and analysed using descriptive statistics and the Pearson chi-square test (with the Yates correction when appropriate), or the two-sided Fisher exact test, the likelihood ratio, the student t-test, or the chi-square for trend, as appropriate. The totals used for the analysis were the number of valid responses for each question.

\section{Stakeholder study}

Twenty-seven hours of taped, semistructured interviews with stakeholders were transcribed and submitted to a formal content analysis (Table 1).

\section{Results of the documentary studies Portuguese literature review}

Following the strategy defined above, only one publication was identified with an explicit reference to VAHPITWP [6]. This opinion document, by the Union of Portuguese Nurses (Sindicato dos Enfermeiros Portugueses), analyses the risk in nursing practice. It refers to microbiological, chemical and radiation hazards as well as equipment, work noise, stress, shift work, age and lifestyles as risk factors in nursing. It is in this context that violence is mentioned. The chapter dedicated to violence refers briefly to the increase of violence in society and underscores factors such as poor security and working hours (being open for $24 \mathrm{~h} /$ day) as explaining the high rate of vandalism against professionals' cars.

This document reports that females and nursing directors are the most vulnerable to attacks, as well as those working in services for the elderly and at emergency and psychiatric units. The second part of this document has 16 real-life stories of nurses who have experienced some of the occupational hazards mentioned above, including one on violence.

\section{Analysis of institutional documents}

Twenty-two official reports on violence from five HCs and two hospitals were analysed. The victims of violence reported all the incidents in writing. The highlights of this analysis were that: most reported violence was verbal; reported violence was equally distributed against nurses $(n=9)$, doctors $(n=9)$ and other personnel $(n=9)$; hospital violence was most reported by nurses (in $6 / 7$ reports involving violence against nurses); nurse-reported violence was mostly from hospitals (in 6/10 reports); HCreported violence was mostly by doctors (in 7/13 HC reports); doctor-reported violence was mostly from HCs (in 6/9 reports involving violence against doctors).

\section{National press analysis}

Nine articles on violence were identified and analysed. The principal highlights of these press reports are that: most (7) press reports referred to violence against doctors; most (7) press reports referred to physical violence; and most (5) press-reported incidents of violence occurred in hospitals. 
Table I: List of stakeholders selected for the study

\begin{tabular}{|c|c|c|c|}
\hline \multirow{2}{*}{$\begin{array}{l}\text { Stakeholder } \\
\text { Union leaders }\end{array}$} & \multicolumn{2}{|l|}{ Comments and number of interviews intended } & \multirow{2}{*}{$\begin{array}{l}\text { Response rate } \\
5(71.4 \%)\end{array}$} \\
\hline & & 7 & \\
\hline $\begin{array}{l}\text { Representatives of professional } \\
\text { associations and professional councils }\end{array}$ & & 5 & $5(100 \%)$ \\
\hline \multirow{7}{*}{$\begin{array}{l}\text { Health managers from the } \\
\text { Department of Health of the Ministry of Health } \\
\text { and the NHS }\end{array}$} & Simple random sample of HCs in the selected health region & 9 & 6* $(66.6 \%)$ \\
\hline & $\begin{array}{l}\text { Simple random sample of hospitals in the selected health } \\
\text { region }\end{array}$ & 9 & 6** $(66.6 \%)$ \\
\hline & Health Department & 3 & $2(66.6 \%)$ \\
\hline & Department of Human Resources & 1 & 0 \\
\hline & Regional and subregional Health Authorities & 8 & $3(37.5)$ \\
\hline & INEM (Institute of Medical Emergencies) & I & I (100\%) \\
\hline & Subtotal & 31 & $18(58.1 \%)$ \\
\hline Total & & 43 & $28(65.1 \%)$ \\
\hline
\end{tabular}

* I joint interview of medical and nursing directors; **All interviews were joint interviews of medical and nursing directors

Table 2: Patterns of violence observed over the 12 months preceding the survey

\begin{tabular}{|c|c|c|c|c|}
\hline \multirow[t]{2}{*}{ Type of violence } & \multicolumn{2}{|c|}{ Self was victim of violence } & \multicolumn{2}{|c|}{$\begin{array}{l}\text { Self witnessed violence against } \\
\text { another health professional }\end{array}$} \\
\hline & $\mathrm{N}$ & $\%$ & $\mathrm{~N}$ & $\%$ \\
\hline Verbal & 74 & 27.4 & & \\
\hline Bullying / Mobbing & 43 & 16.5 & & \\
\hline Discrimination & 21 & 8.0 & & \\
\hline Physical violence & 7 & 2.6 & 21 & 8,1 \\
\hline Sexual harassment & 7 & 2.7 & & \\
\hline Any type & 102 & 36.8 & & \\
\hline
\end{tabular}

\section{Results of the hospital case study Study population}

Two hundred and seventy-seven hospital workers answered the questionnaire $(80 \%$ response rate), although the response rate varies from question to question. There were 54 males $(20.1 \%)$ and 214 females (79.9\%); $50.8 \%$ of the workers were between 30 and 44 years of age.

\section{Violence against health professionals}

The different patterns of violence observed are summarised in Table 2 . In none of the cases of physical violence was a weapon used.

\section{Violence by professional group}

The percentage of any professional group reporting any type of violence is summarized in Table 3. Globally violence is most frequently experienced by nurses, although some specific violence types are most common in other personnel groups.

\section{Violence by sex of the victims}

All types of violence (except for sexual harassment) are most prevalent for male health professionals (although never statistically significant) (Table 4).

\section{Results of the health centre case study Study population}

In the HC complex, 221 persons answered the questionnaire (overall response rate of $86 \%$ ) although the response rate varies from question to question. There were 50 males (23\%) and 168 females (77\%). The bulk of the workers were between 35 and 54 years of age.

\section{Violence against health professionals}

The different patterns of violence observed are summarised in Table 5. In none of the cases of physical violence was a weapon used. 
Table 3: Frequency (and percentage) of any professional group reporting any type of violence in the hospital.

\begin{tabular}{|c|c|c|c|c|c|c|c|c|c|}
\hline Type of violence & $\begin{array}{l}\text { Hospital } \\
\text { administratorl } \\
\text { director }\end{array}$ & Nurse & $\begin{array}{l}\text { Administrati } \\
\text { ve personnel }\end{array}$ & Doctor & $\begin{array}{l}\text { Clinical } \\
\text { auxiliaries }\end{array}$ & $\begin{array}{l}\text { Diagnostic } \\
\text { paramedics }\end{array}$ & $\begin{array}{l}\text { Other with } \\
\text { university degree }\end{array}$ & $\begin{array}{l}\text { Other } \\
\text { auxiliaries }\end{array}$ & Other \\
\hline Verbal* & I (20) & $29(4 I)$ & $3(12)$ & $13(42)$ & $13(19)$ & $6(24)$ & $\mathrm{I}(17)$ & $2(14)$ & $6(27)$ \\
\hline Bullying / Mobbing* & I (20) & $17(25)$ & I (5) & $7(23)$ & $7((I I)$ & $2(9)$ & $2(33)$ & 0 & $6(29)$ \\
\hline Discrimination** & 0 & $9(13)$ & I (4) & I (3) & $5(8)$ & I (4) & 0 & I (7) & $3(15)$ \\
\hline Physical** & 0 & $5(7)$ & 0 & 0 & I (2) & 0 & 0 & 0 & I (4) \\
\hline Sexual harassment ${ }^{* *}$ & 0 & $5(7)$ & 0 & 0 & I (2) & 0 & 0 & I (7) & 0 \\
\hline Any type* & $2(40)$ & $38(54)$ & $5(20)$ & $16(52)$ & $19(28)$ & $8(32)$ & $2(33)$ & $3(21)$ & 9 (39) \\
\hline
\end{tabular}

* Likelihood ratio $\mathrm{p}<0.05$; ** likelihood ratio $\mathrm{p}>0.05$

Table 4: Percentage by gender that suffered a specific type of violence in the hospital.

\begin{tabular}{lcc}
\hline Type of violence & Sex & Male \\
\cline { 2 - 3 } & & Female \\
\hline Verbal & 33 & 26 \\
discrimination & 10 & 7 \\
Bullying / Mobbing & 22 & 15 \\
Physical & 6 & 2 \\
Sexual harassment & 2 & 3 \\
Any type & $\mathbf{4 6}$ & $\mathbf{3 5}$ \\
\hline
\end{tabular}

Table 5: Patterns of violence observed over the 12 months preceding the survey in the Health Center Complex.

\begin{tabular}{lll}
\hline Type of violence & Self was victim of violence & $\begin{array}{l}\text { Self witnessed violence against other health } \\
\text { professionals }\end{array}$ \\
\hline $\begin{array}{l}\text { Any type } \\
\text { Physical }\end{array}$ & $133(60 \%)$ & $7(4 \%)$ \\
Against property & $7(3 \%)$ & \\
Psychological & $32(15 \%)$ & $113(55 \%)$ \\
Verbal & $117(54 \%)$ & $41(20 \%)$ \\
Bullying / Mobbing & $111(51 \%)$ & $11(5 \%)$ \\
Discrimination & $50(23 \%)$ & $1(0,5 \%)$ \\
Sexual & $9(4 \%)$ & $2(1 \%)$ \\
\hline
\end{tabular}

Table 6: Frequency (and percentage) of any professional group reporting any type of violence in the Health Center Complex.

\begin{tabular}{|c|c|c|c|c|c|c|c|c|c|c|}
\hline $\begin{array}{l}\text { Type of } \\
\text { violence }\end{array}$ & Nurses & Administrative & GP & $\begin{array}{l}\text { Clinical } \\
\text { auxiliaries }\end{array}$ & $\begin{array}{l}\text { Cleaning } \\
\text { personnel }\end{array}$ & $\begin{array}{l}\text { Other } \\
\text { medical } \\
\text { specialty }\end{array}$ & $\begin{array}{l}\text { Other with } \\
\text { university } \\
\text { degree }\end{array}$ & Security & $\begin{array}{l}\text { Diagnostic } \\
\text { paramedics }\end{array}$ & Other \\
\hline Verbal & $35(67)$ & $37(7 \mathrm{I})$ & $22(44)$ & $5(24)$ & $3(20)$ & $2(25)$ & $5(7 \mid)$ & I (20) & I (33) & 0 \\
\hline Bullying / Mobbing & $12(23)$ & $18(35)$ & $15(3 \mid)$ & $2(9)$ & 0 & $\mathrm{I}(\mathrm{II})$ & $1(14)$ & I (20) & $2(67)$ & 0 \\
\hline Against property & $8(15)$ & $7(14)$ & $12(24)$ & 0 & 0 & $2(25)$ & I (14) & 0 & 0 & 0 \\
\hline Discrimination & $3(6)$ & $3(6)$ & $2(4)$ & 0 & 0 & 0 & $1(14)$ & 0 & 0 & 0 \\
\hline Physical & $4(8)$ & 0 & $2(4)$ & 0 & 0 & 0 & 0 & 0 & 0 & 0 \\
\hline Sexual & 0 & I (2) & I (2) & 0 & 0 & 0 & 0 & 0 & 0 & 0 \\
\hline Any type & $36(74)$ & $35(70)$ & $29(58)$ & $6(29)$ & $4(29)$ & $3(33)$ & $3(60)$ & $2(40)$ & I (33) & 0 \\
\hline
\end{tabular}




\section{Violence by professional group}

The percentage of any professional group reporting any type of violence is summarized in Table 6 . Violence of any sort and physical violence are most frequently experienced by nurses. Verbal violence and bullying / mobbing are most frequently experienced by administrative personnel. Violence against property is most frequently directed against the property of doctors. General practitioners and administrative personnel were the only two groups reporting cases of sexual harassment.

\section{Violence by the sex of the victims}

Except for sexual harassment (only two cases, one male and one female), all types of violence are most prevalent among female health professionals (the difference is statistically significant for verbal violence, two-sided Fisher exact test $\mathrm{p}=0.022$ and for any type of violence, two-sided Fisher exact test $\mathrm{p}=0.028$ ) (Table 7).

\section{Results of the stakeholder study}

The results of this section are divided into three parts, referring respectively to the opinions of (i) union leaders, (ii) leaders of professional councils and associations and (iii) NHS managers.

\section{Union leaders}

VAHPITWP was considered a very important problem by all the interviewees. Verbal aggression was perceived as very frequent. The most worrisome type of violence was identified by two of the interviewees as bullying / mobbing, by colleagues and users alike. Physical violence was considered important for doctors and nurses who have to deal directly with patients, but not for other health professionals. "Institutional violence" was mentioned by two of the interviewees as resulting from the lack of competence of the managers of health services. Sexual harassment and discrimination were considered infrequent and it is believed that, when it happens, it is not reported, particularly when the person responsible for the violence is a more senior professional or manager.

One of the reasons why VAHPITWP was considered important was the growing number of cases being reported and their increasing severity, particularly of physical violence. According to the interviewees, this increase in the frequency of violence reflects two phenomena of modern society: on the one hand, the greater visibility of violence in modern culture and on the other, a growing perception by citizens of their rights, with the corresponding increase in the level of demands. This increased awareness of rights has not been accompanied by a similar increase in civic education.

No change has been observed as to the site of occurrence of violence: it was still perceived as being most common in the hospital emergency departments, in ambulatory care services and during home visits.

\section{Leaders of professional councils and associations}

All the leaders considered VAHPITWP an important issue.

The President of the Medical Council considered verbal violence the most frequent, particularly when doctors worked alone, such as GPs in the HCs. Nevertheless, the most worrisome form of violence, even if less frequent, is physical violence. Bullying / mobbing of doctors by patients, particularly in relation to access to sick leave certificates, is also quite significant. Doctor-versus-doctor violence was acknowledged. There was recollection of episodes of xenophobia, particularly against Brazilian colleagues, but no recollection of sexual harassment.

According to this interviewee, the pattern of violence has evolved. Verbal violence has increased the most. Physical violence has increased, particularly over the last 13 years. Violence among colleagues is also more frequent now than in the past, mostly because of too much work and overtime. This increase in the level of observed violence must also be seen in the context of a society also more violent now than in the past.

The most violent workplaces are the HCs. The reason is that in the HCs patients feel at home and are very familiar with the health personnel.

For the President of the Nursing Council there is a need to better understand the behaviours that result in aggression. This is important because of the impact of VAHPITWP on the quality of the care provided.

The most frequent and the most worrisome aggressive behaviours are those that lead to verbal aggression. Physical aggression is a minor problem and harassment and discrimination are very infrequent.

Violence, particularly verbal, increased significantly.

Violence is most frequently observed in emergency services, where nurses are most frequently the first-contact professionals.

For the other professional associations, different positions emerge.

For some, the most worrisome type of violence is that which results from institutional harassment because doctors may interfere with established interests, political and economic. This is particularly true in the case of public health doctors. This type of violence was also acknowledged by one other professional association, particularly 
Table 7: Percentage by gender that suffered a specific type of violence in the Health Center Complex

\begin{tabular}{|c|c|c|}
\hline Type of violence & Male & Female \\
\hline Verbal & 35 & 55 \\
\hline Bullying / Mobbing & 14 & 25 \\
\hline Against property & 13 & 15 \\
\hline Discrimination & 2 & 5 \\
\hline Physical & 2 & 3 \\
\hline Sexual & 2 & 0.6 \\
\hline Any type & 41 & 61 \\
\hline
\end{tabular}

in situations of competition for professional leadership positions - the loser is frequently persecuted and repeatedly humiliated by the winner, forcing many professionals to look for alternative workplaces in which to practice.

Violence among colleagues was also considered very frequent. Verbal aggression, as well as psychological pressure, appears masked as "threats of disciplinary procedures for negligence". Racial discrimination was not acknowledged as being worrisome. Sexual harassment was infrequent but "somewhat worrisome", as such instances are usually taken to court. As the proportion of female professionals increases, sexual harassment seems also to increase.

Once again, aggression against GPs was seen as most worrisome. GPs work alone in their consulting rooms. Also, the proportion of women GPs is higher than in other medical groups. Violence was perceived as particularly frequent against professionals working after normal working hours.

From the perspective of its impact, the most worrisome type of violence is the VAHPITWP that recurs daily: not physical violence - which is infrequent, although with more serious consequences - but rather bullying / mobbing.

Although VAHPITWP was seen as a very worrisome phenomenon on the increase, it is the opinion of interviewees that it must be seen in the context of a society ever more violent and less tolerant. While in the past violence was most frequent in the emergency services, now it is more generalised. One factor that contributes to this increase in VAHPITWP is the perception of health as "a most important value". Another factor is the increased professional and academic status of the nursing profession. Users are also different: better-informed and more sophisticated than in the past, more aware of their rights, they come to the health services with a more demanding attitude. Among the users some ethnic groups, as well as the drug abusers, are seen as particularly violent.

\section{NHS managers}

The NHS managers are divided into three groups: HC managers, hospital managers and managers of regional and central health departments.

\section{Health centre managers}

We interviewed the medical directors of six HCs. Only one of these interviews was a joint interview with the nursing director.

All the interviewees considered VAHPITWP a very important problem "(...) the most frequent type of violence is verbal violence (...) it happens every day. It may become extremely violent (...) we have been through serious episodes of violence". It is most frequent against nurses and administrative personnel. One of the HC managers considered physical violence as the most serious form of violence observed, followed by bullying / mobbing of the users. But all acknowledged all the forms of violence, although giving them different priorities. Sexual harassment was considered infrequent or absent "the white coat defends us, it is a dissuasive element (...)". Discrimination was also considered very infrequent.

Some said that VAHPITWP was becoming more frequent, while others claimed that violence was not becoming more frequent but had become more serious. These changes were attributed to the lack of information by the users and to poor communication skills of the health personnel. VAHPITWP reflected the fact that we "live in a violent world, people when coming to the HC bring with them a significant amount of stress, they are in a hurry (...) people are subjected to a lot of pressure and a visit to the HC is like a safety valve".

Violence was considered inherent to the NHS in situations such as short-term contracts. This reflected violence as part of the general societal culture. The media were an important factor in perpetuating this type of violence. The rights movement, unlinked to a responsibilities movement was also an important explanation of the current trend: people claim more and more rights but do not rec- 
ognise their responsibilities. This is partially associated with the public servant image that users have of health professionals "I pay a lot of taxes to ensure your income so you had better produce the goods". Another pattern emerging, particularly during home visits, is the blaming of the health care services for all social ills.

\section{Hospital managers}

In each of the six hospitals, we interviewed jointly the medical and nursing directors.

VAHPITWP was referred to as a natural expectation in the hospital setting that should not be seen out of this context. It is a "professional hazard". It was also seen as a mechanism to try to obtain the attention that the patient feels entitled to. It must be perceived more as a conflict rather than conscious, deliberate and systematic violence. It is important to understand that not all professionals see aggression as aggression against themselves as professionals; they ignore it because the professional tries to understand the reactions of the patients in the context of his or her situation:

"This phenomenon of violence against health professionals (...) was very frequent when XXX (the Minister of Health who during the 1980s initiated a campaign to "moralize" public sector professional practice) was the minister of health. She encouraged campaigns against doctors and patients felt encouraged (to take positions such as) 'it is now that I am going to get at them'. Otherwise it occurs sporadically ... People protest very easily. They protest very easily and become aggressive against some professionals for any little thing".

For one interviewee, physical violence was the most visible type of VAHPITWP, standing side by side with psychological and verbal violence. For all the others, verbal violence was the most frequent type of VAHPITWP and physical violence was considered infrequent. For one, bullying / mobbing was uncommon, while another acknowledged the bullying / mobbing exerted by relatives over the professionals as "not uncommon". This type of violence was reflected in the frequent use of expressions such as: "you guys work here, but we are paying your salaries, so you must do as we wish (...), if I catch you outside (...)". Sexual harassment and racial discrimination were considered infrequent. Sexual harassment, when it happens, has to do with illness in the elderly or in services directed at teenagers or young adults. Infrequent complaints of racial discrimination were presented by some black doctors against patients. This has usually to do with dissatisfaction in relation to the care provided, mixed with the racial issue. A new type of aggression has to do with attempts to intimidate the professional with threats of denouncing him or her through the media.
VAHPITWP is most frequent in the hospital emergency department, because that is where disturbed individuals (drug addicts, alcoholics, mentally disturbed, people in pain, etc.) are most frequently found. Most cases of physical violence occur there.

VAHPITWP has been on the increase for the past 20 years. This has to do with a change of the dependency of patients in relation to professionals, giving rise to situations of violence against patients; this has changed and patients have more rights now. Verbal and physical violence are on the increase. Violence begets violence, and in a violent society repercussions must be expected in all sectors, including health:

"Violence is increasing in Portuguese society and health suffers from this influence. The battle for audiences promotes a witch hunt for mistakes and negligence in health, resulting in a climate of untrustworthiness and insecurity in relation to health care. (...) promoting in the public's opinion an expectation of better health care, far above the supply capacity. All this primes people for violence as soon as there is a deviation from the expectations, resulting in aggression and animosity. If there is no capacity for attentive listening, persuasion and negotiation, the result is violence".

In terms of the evolution of violence, one interviewee perceived it as being less frequent against doctors but all the others acknowledged it as a problem either on the increase or stable (one interviewee) but of similar frequency for all professional groups (more frequent against nurses, according to one of the interviewees). This is particularly true for verbal violence. There are also changes in the pattern of verbal violence: while in the past it was more like verbal lashing, now it is more verbal threats. Some of the respondents are not sure that physical violence is more frequent, but they perceived the physical violence as being of "a different intensity".

The managers of the regional health authorities and of central departments of the ministry of health

We interviewed six public sector health managers at central and regional level.

All the interviewees considered VAHPITWP as an important problem. As to the most important form of VAHPITWP, the opinions varied from four that considered psychological violence, including verbal violence (one) and bullying / mobbing (one) as the most important. One of the interviewees considered that physical violence was not very relevant and another one considered it worrisome, reflecting a lack of mechanisms to ensure the security of the health professionals, particularly in situations when health professionals meet their clients behind closed doors. Physical violence was also considered very 
important for emergency care crews called to provide emergency non-institutional care. Verbal aggression was also identified as frequent against health professionals manning emergency telephone lines and against administrative health personnel. Sexual harassment was considered infrequent, not visible or unknown. Physical violence was perceived as, if not the most important, the most worrisome, the most visible and the one that most frequently led to court cases.

One of the interviewees considered that racial discrimination was most frequent against the users of the health services rather than towards the professionals. Another stated that racial discrimination against health professionals existed and that it might amplify other forms of violence.

Regarding the observed trends in the evolution of VAHPITWP, most interviewees considered that VAHPITWP in general was on the increase. The current level of VAHPITWP was partly attributed to the "eternal" disorganization of the health services and to the lack of management skills.

"Some people have too much power (...) they misunderstand their role (...) and this leads to the creation of barriers to the personnel working under them. This is particularly visible (...) in hospitals".

One other interviewee considered that current violence trends reflected the level of violence in society. A third attributed it to greater media visibility, and because people more frequently now than in the past dare to challenge professional opinions. One considered that we may not be seeing an increase in the incidence of violence but rather a greater visibility, because of the role of the media or even, according to another, due to intensity of the violence observed today. A new form of violence, violence against property, is associated with the emergence of drug addicts.

Violence was perceived as most frequent in HC consultation rooms and reception desks and in hospital emergency care departments. In hospitals, violence by patients' escorts was considered more frequent than in HCs

\section{Conclusions \\ On the methods}

The methodology chosen for the present study has provided a large amount of very useful information about workplace violence in the Portuguese health sector, which is likely to be of great importance for further development of the issue in Portugal. The fact that the information, by and large, comes from people in positions of power at different levels of the health sector (including union leaders) is also likely to increase commitment at a senior manage- ment level for the implementation of future strategies with regard to violence prevention.

But because of the stakeholder focus on people in managerial or representative positions, the voice of health sector employees has not fully been heard. For this reason, we cannot be fully reassured that the report correctly reflects definitional issues and problem description.

The study also neglects the nongovernmental sector, a minor but growing partner in health care provision.

Lastly, the most rare types of violence, such as physical violence and sexual harassment, need a different methodological approach even to achieve a better characterization.

Despite these limitations, this remains the only formal Portuguese study on VAHPITWP. These limitations and the complexity of the problem require some care in the inference of relevant conclusions.

\section{On the patterns of violence}

Measured violence

Violence seems much more frequent in the HC than in the hospital.

In order of most frequent reporting, verbal violence is the most frequent, followed by bullying / mobbing, discrimination, physical violence and sexual harassment. The HC data on violence against personal property suggest that it is very prevalent, but we have no data on this for the hospital study.

All types of violence in the HCs are also most frequently directed against female health workers and in the hospital, against male workers.

Some results suggest differences in the patterns of violence, in the health facilities studied: verbal violence is most frequent against HC nurses and administrative personnel; physical violence seems most frequent against nurses in both the HC and the hospital; sexual harassment seems a particularly frequent problem of hospital nurses; bullying / mobbing is most frequent against HC GPs and administrative personnel; discrimination seems a phenomenon felt mostly in the hospital by nurses, other professionals with a university degree and the "other" category.

An important aspect is that, in both health facilities where the study was conducted, the whole range of types of violence was identified. This suggests that all HCs and hospitals need guidelines on how to handle the whole range of them. 


\section{Reported violence}

On the type of violence that health workers feel necessary to report, we have three sources of data: the hospital, the HCs and the institutional documents studies.

Twenty-two official reports on violence from five HCs and two hospitals were analysed. Most reported violence was verbal, reflecting the results of the hospital and the HC study. But, taking the HC complex case study as the standard, HC administrative personnel and nurses seem to underreport VAHPITWP, when compared to doctors

It seems that some forms of violence such as discrimination, bullying / mobbing and sexual harassment will not be properly addressed by the current system of written report books, which are open to all colleagues.

\section{Violence as seen by the media}

Media reports on violence do not reflect the true dimensions of the problem. The media reflects violence as being physical and against hospital doctors, when in reality it is a much more serious problem, with dimensions other than the physical dimension, in HCs and against nurses and administrative staff. These point to the need to clearly brief the media professionals on the results of this study.

\section{Violence as seen by different stakeholders}

All stakeholders considered VAHPITWP an important problem. They clearly identified verbal violence as the most frequent and physical as the most serious and worrisome, reflecting a reliable empathy with the reality as measured by the hospital and HC studies and serving as a measure of external validity of their results. Nevertheless, stakeholders seem to underestimate the true dimension of the problem of discrimination.

This study allows us to conclude that violence is frequent but underreported. The underreporting is partly associated with the means available to do so, that do not guarantee the privacy of the report.

Of the different types of violence, all our studies confirm that verbal violence is the most frequent. Discrimination, not infrequent in the hospital and HC studies, seems to be underestimated by the stakeholders interviewed.

\section{Annex: Definitions of violence (adapted from ILO et al., 2002) [7] Physical violence}

The use of physical force against another person or group, that results in physical, sexual or psychological harm. Includes beating, kicking, slapping, stabbing, shooting, pushing, biting, spitting, pinching, among other actions.

\section{Psychological violence}

Intentional use of power, including threat of physical force, against another person or group, that can result in harm to physical, mental, spiritual, moral or social development. Includes verbal abuse, bullying/mobbing, harassment, and threats.

\section{Any type of violence}

Refers to the use of either physical or psychological violence or both.

\section{Terms frequently used}

Physical and psychological violence often overlap in practice, making any attempt to categorize different forms of violence very difficult. Some of the most frequently used terms related to violence are presented in the following list.

\section{Assault/Attack}

Intentional behaviour that harms another person physically, including sexual assault

\section{Abuse}

Behaviour that humiliates, degrades or otherwise indicates a lack of respect for the dignity and worth of an individual.

\section{Bullying / Mobbing}

Repeated and over time offensive behaviour through vindictive, cruel or malicious attempts to humiliate or undermine an individual or groups of employees.

\section{Discrimination}

Any conduct based on age, disability, HIV status, domestic circumstances, sex, sexual orientation, gender reassignment, race, colour, language, religion, political, trade union or other opinion or belief, national or social origin, association with a minority, property, birth or other status that is unreciprocated or unwanted and that affects the dignity of men and women at work.

\section{Sexual harassment}

Any unwanted, unreciprocated and unwelcome behaviour of a sexual nature that is offensive to the person involved, and causes that person to be threatened, humiliated or embarrassed.

Threat

Promised use of physical force or power (i.e. psychological force) resulting in fear of physical, sexual, psychological harm or other negative consequences to the targeted individuals or groups. 
Victim

Any person who is the object of act(s) of violence or violent behaviour(s) as described above.

\section{Perpetrator}

Any person who commits act(s) of violence or violent behaviour(s) as described above

\section{Workplace}

Any health care facility, whatever the size or location (urban or rural) and the type of service(s) provided, including hospitals, health care centres, clinics, community health posts, rehabilitation centres, long-term care facilities, general practitioners' offices, other independent health care professionals' offices. In the case of services performed outside the health care facility, such as ambulance services or home care, any places where such services are provided will be considered a workplace.

\section{List of abbreviations \\ EU - European Union \\ GP - General practitioner \\ HC - Health centre \\ NHS - National Health Service \\ RHA - Regional Health Authority}

VAHPITWP - Violence against health professionals in the workplace

\section{Competing interests}

None declared.

\section{Authors' contributions}

Paulo Ferrinho was the overall coordinator. All authors assisted with the planning and protocol development. Inês Fronteira coordinated the hospital fieldwork and carried out the corresponding analysis. Inês Fronteira, Isabel Craveiro, Claudia Conceição and Ana Rita Antunes collaborated in the hospital data collection. Inês Fronteira, Ana Rita Antunes and Paulo Ferrinho carried out the fieldwork for the stakeholders study. Isabel Craveiro and Ana Rita Antunes carried out the content analysis of the stakeholder study. André Biscaia facilitated the interface with the health centre. Paulo Ferrinho coordinated the health centre fieldwork and all researchers collaborated in the data collection. Paulo Ferrinho carried out the analysis of the health centre data. All authors commented on the different drafts of the research reports and read and approved the manuscript submitted for publication.

\section{Acknowledgements}

This study was initiated by an international consortium of the International Labour Organisation (ILO), the World Health Organization, the International Council of Nurses and Public Service International. The study shared a core joint protocol, definitions of violence and questionnaire with other studies in other countries. The Portuguese component of the study was funded by the ILO, the AGO, the Sindicato dos Enfermeiros Portugueses (Nurses Union) and the APMCG (Portuguese General Practitioners Association).

\section{References}

I. Craveiro I, Ferrinho P: Planear estratégicamente: a prática no SNS. Revista Portuguesa de Saúde Pública 200I, 2:27-37.

2. Portugal. Ministério da Saúde: Saúde um compromisso - uma estratégia de saúde para o virar do século 1998-2002. Lisboa 1999.

3. Portugal. Direcção Geral da Saúde: Ganhos de Saúde em Portugal. Ponto de situação. Lisboa 2002.

4. Ferrinho P, Pereira Miguel J, eds: The Health Status in The EU. Narrowing the Health Gap. Unpublished Report to the European Commission. Lisbon 200I.

5. Biscaia A, Conceição C, Martins J, Ferrinho P: Politique et gestion des ressources humaines dans le secteur de la Santé au Portugal - controverses et problématiques actuelles. Cahiers Soc Dem Med 2003 in press.

6. Sindicato dos Enfermeiros Portugueses: Risco, Penosidade e Insalubridade - uma realidade na profissão de enfermagem. Lisboa 2000 .

7. ILO/ICN/WHO/PSI: Framework guidelines for addressing workplace violence in the health sector. Unpublished report. Geneva 2002.
Publish with Biomed Central and every scientist can read your work free of charge

"BioMed Central will be the most significant development for disseminating the results of biomedical research in our lifetime. " Sir Paul Nurse, Cancer Research UK

Your research papers will be:

- available free of charge to the entire biomedical community

- peer reviewed and published immediately upon acceptance

- cited in PubMed and archived on PubMed Central

- yours - you keep the copyright

Submit your manuscript here:

http://www.biomedcentral.com/info/publishing_adv.asp 